\title{
A Convenient Domino Access to Substituted Alkyl 1,2-Dihydropyridine-3-carboxylates from Propargyl Enol Ethers and Primary Amines
}

\author{
Dr. David Tejedor, ${ }^{[\mathrm{a}],[\mathrm{b}]}$ Miss Gabriela Méndez-Abt ${ }^{[\mathrm{a}],[\mathrm{b}]}$ and Dr. Fernando García-Tellado*[a],[b]
}

\begin{abstract}
[a] Department of Química Biológica y Biotecnología, Instituto de Productos Naturales y Agrobiologia, Consejo Superior de Investigaciones Científicas, Avda. Astrofísico Francisco Sánchez 3, 38206 La Laguna, Tenerife, Spain

${ }^{[b]}$ Instituto canario de Investigación del Cáncer, Spain (www.icic.es)
\end{abstract}

Fax: (+)34922-260135

E-mail: fgarcia@ipna.csic.es; dtejedor@ipna.csic.es

http://www.ipna.csic.es/departamentos/qbb/qb/

To the Professor José Barluenga Mur in his $70^{\text {th }}$ birthday

Azatrienes constitute important synthetic blocks for the synthesis of six-membered nitrogen heterocycles. ${ }^{[1]}$ In particular, thermally-driven $6 \pi$-electron electrocyclic ring closure $(6 \pi$-azaelectrocyclization) of 1-azatrienes constitutes a main synthetic avenue to pyridines and 1,2dihydropyridines (Eq. [1]). ${ }^{[2]}$ Pivotal to this strategy is the chemical access to the functionalized 1azatriene unit. Currently, these units are assembled in situ and directly used to construct the nitrogen heterocycle. In particular, the Knoevenagel-condensation of iminium ions with vinylogous amides has proved to be a successful strategy for the assembly of these units in route to chiral 1,2dihydropyridines. ${ }^{[3]} \mathrm{We}$ envisioned that an alternative and more direct access to 1 -azatrienes could rely on the reaction of primary amines 4 and 2,4-dienals 3 (Scheme 1), ${ }^{[4]}$ which in turn could be obtained via a thermally-driven [3,3] propargyl- Claisen rearrangement of easily accessible propargyl vinyl ethers 1. Precedents for the metal-catalyzed version of this rearrangement ${ }^{[5],[6]}$ have shown that the substitution pattern of the propargyl vinyl ether plays an important role on both the reaction conditions and the chemical outcome of the rearrangement. Under metallic catalysis, propargyl vinyl ethers $\mathbf{1}$ rearrange to allenes 2 which can reorganize to furans ${ }^{[5 \mathrm{c}]}$ or $2 \mathrm{H}$-pyrans ${ }^{[5 \mathrm{~b}]}$ or dihydropyrans ${ }^{[5 \mathrm{~d}]}$ via selective 5-exo-dig or 6-endo-trig cyclizations, or they can afford substituted pyrroles ${ }^{[5 a]}$ by one-pot condensation with a primary amine and subsequent metal-catalyzed 5-exo-dig cyclization. We hypothesized that allenes $\mathbf{2}$, in the absence of metals, would reorganize to 2,4-dienals $\mathbf{3}$ via a thermallyallowed prototropic rearrangement biased by the ester group allocated at the $\alpha$-position of both the allene and aldehyde functions [Scheme 1]. ${ }^{[7]}$ In the presence of a primary amine, 2,4-dienal 3 could form the corresponding functionalized 1 -azatriene $\mathbf{5}$, which in turn would rearrange to the 1,2dihydropyridine derivative 6 via a $6 \pi$-aza-electrocyclization. Because the $[3,3]$ propargyl enol ether rearrangement is expected to be compatible with the presence of a primary amine, we anticipated that the reaction could be carried out in a domino fashion. ${ }^{[8]}$ Overall, the entire process would constitute a novel, modular and metal-free domino synthesis of tetrasubstituted alkyl 1,2-dihydropyridine-3carboxylate derivatives from primary amines and propargyl enol ethers through a propargyl-Claisen rearrangement - isomerization - amine condensation - $6 \pi$-aza-electrocyclization process. Importantly, the ester group, which would be playing a vital role as a reactivity controlling element during the process, would be incorporated into the final 1,2-dihydropyridine unit as a convenient chemical handle for further generation of complexity and/or chemical diversity. Overall, in terms of diversity-oriented synthesis, 1,2-dihydropyridines $\mathbf{6}$ could be generated in a modular manner with four possible points for diversity generation $\left(\mathrm{R}^{1}-\mathrm{R}^{4}\right)$ and a chemical handle for further elaboration (Figure 1). In addition, 
propargyl enol ethers 1 are easily accessible starting materials spanning a wide substitution pattern. ${ }^{[9]}$ In this communication we report on the proof of concept of this strategy and its extension to the synthesis of nicotinic acid derivatives.

We started this work studying the reaction of $p$-anisidine (4a) and propargyl enol ether $\mathbf{1 a}$ (Scheme 2). After some experimental work, we found that microwave irradiation ${ }^{[10]}$ of a toluene solution of $\mathbf{1 a}$ $\left(150\right.$ watt, $\left.120^{\circ} \mathrm{C}, 30 \mathrm{~min}\right)$ afforded the corresponding dienal $\mathbf{3 a}$ which could be isolated as a mixture of $\mathrm{E} / \mathrm{Z}$ (1:1) isomers in 59\% yield after flash-chromatographic purification (Scheme 2). This finding corroborates the advanced importance of the conjugated electron-withdrawing group at the terminus of the enol function (Figure 1, reactivity-code element). Notably, after the rearrangement, this group is placed at the $\mathrm{sp}^{3}$-position of intermediate allene $\mathbf{2}$ (Scheme 1), biasing the energetically favored prototropic 1,3-rearrangement of allene 2 to the fully conjugated dienal 3a. ${ }^{[11]}$ Subsequent treatment of dienal 3a with $p$-anisidine (4a) (1 equiv) at room temperature in toluene for $1 \mathrm{~h}$ delivered 1,2dihydropyridine 6aa in quantitative yield. It is remarkable that the double bond geometries do not have a noticeable effect on the yield of this cyclization. ${ }^{[12]}$ Once we proved that our synthetic concept could be conveniently carried out in a two step manner, we next studied the domino version of this process by the direct reaction of the amine and the propargylic derivative 1a under microwave irradiation. After some experimental efforts, we found that the microwave irradiation of a toluene solution $(5 \mathrm{~mL})$ of $p$ anisidine (4a) $\left(1.1 \mathrm{mmol}\right.$.) with $1 \mathbf{a}(1 \mathrm{mmol})\left(150\right.$ watt, $120{ }^{\circ} \mathrm{C}$, closed vessel, $\left.30 \mathrm{~min}\right)$ afforded 1,2dihydropyridine 6aa with an impressive efficiency (quantitative yield) (Scheme 2).

Once the proof of concept was established, we next studied the scope of this reaction with regard to the propargylic component and the amine (Table 1). In general, the reaction presented a broad spectrum for the amine although aromatic amines gave better yields than aliphatic amines (compare entries 1, 15 and 16 with entries 10-14). The effect of diastereo-induction by the amine component was studied with the commercial amine 4e, which afforded chiral 1,2-dihydropyridine 6ae with a significant 50\% de (entry 13). Presumably, other more sterically demanding chiral amines would introduce higher levels of stereo-induction in this reaction. ${ }^{[13]}$ The substitution pattern of the propargylic unit $\mathbf{1}$ was also studied. Both aliphatic and aromatic substituents were tolerant in the terminal position of the triple bond $\left(\mathrm{R}^{1}\right)$ (entries 1-6). It is remarkable that unsubstituted derivative $\mathbf{1 b}$ gave the poorest yield even under forced conditions (entry 2). This result could be pointing out to the necessity of some conformational control in this kind of processes (a substituent biased conformational control) or/and a certain degree of substitution at the terminal double bond. Propargylic derivatives $\mathbf{1 g}$ and $\mathbf{1 h}$ featuring a substituent at the O-terminus of the enol function reacted with $p$-anisidine (4a) to give the corresponding pentasubstituted 1,2-dihydripyrines 6ga and 6ha although in low yields and under vigorous conditions (300 watt, $150{ }^{\circ} \mathrm{C}, 3 \mathrm{~h}$ ) (entries 7-8). ${ }^{[14]}$ This fact reflects the difficulty for ketimine formation under these conditions and its diminished reactivity for the $6 \pi$-aza-electrocyclization reaction. Substitution at the $\mathrm{sp}^{3}$-propargylic position $\left(\mathrm{R}^{2}\right)$ was found to be dependent on the nature of substituent $\mathrm{R}^{1}$. Whereas $R^{2}$ could be hydrogen, aliphatic or aromatic for terminal alkynes $\left(R^{1}=H\right)$ (entries 1-4) and aromatic for internal alkynes $\left(\mathrm{R}^{1}=\mathrm{Ph}\right.$ or $c \mathrm{Hex}$ ) (entries 5-6), the combination of $\mathrm{R}^{2}=\mathrm{Alk}$, and an internal alkyne (i.e. 7a and 7b, Eq. (3)) did not afford 1,2-dihydropyridines. Instead, mixtures of compounds 8 and 9 were systematically obtained. Importantly, the same mixtures were obtained when these reactions were performed in the absence of the amine [Eq. (3)]. These results seem to point out to a new reaction pathway involving different thermally-driven rearrangements of the 2,4-dienal $\mathbf{3}$ intermediate. The study and synthetic utility of this interesting transformation are in progress in our lab.

With regard to the vinyl functionality tolerance, propargyl enol ether $1 \mathbf{i}$ bearing a $\mathrm{SO}_{2} \mathrm{Tol}$ as the electron withdrawing group afforded the corresponding 1,2-dihydropyridine 6 ia in very good yield (80\%) (entry 9).

Finally, the domino reaction with enantiopure propargyl derivative (R)-1a (prepared from enantiopure (R)-1-phenylprop-2-yn-1-ol and methyl propiolate) and $p$-anisidine (4a) afforded the expected product 6aa in racemic form (Table 1, entry 17). Observe that the chiral information present in the starting propargyl enol ether is completely lost in the rearrangement-isomerization process previous to the ketimine formation. 
As a logical extension of this methodology, we attempted its application to the domino synthesis of pyridines 10 featuring a biologically and chemically relevant nicotinic acid motive (Scheme 3). ${ }^{[15]}$ Obviously, implementation of this methodology required an additional step to convert the 1,2dihydropyridine intermediate into the corresponding pyridine via an elimination reaction. Methoxyamine has proved to be an excellent amine derivative for this kind of transformations. ${ }^{[4 b]}$ Accordingly, the microwave irradiation of an ethanolic mixture of propargyl enol ether $1 \mathbf{a}(1 \mathrm{mmol})$ and $\mathrm{MeONH}_{2} \mathrm{HCl}(1.1 \mathrm{mmol})$ in the presence of $\mathrm{NaOAc}(50 \mathrm{~mol} \%)$ yielded the methyl 2-phenyl-4pyridinecarboxylate (10a) in a convenient $54 \%$ yield (4\% of transesterification product) (Scheme 3 ). A similar result was obtained with propargylic derivative 1e (52\% as a $\sim 3: 1$ mixture of methyl and ethyl esters). Derivative 1j featuring an ethyl ester group at the enol position afforded, under the same conditions, the expected pyridine $\mathbf{1 0 j}$ in $55 \%$ yield. To the best of our knowledge, this is the first example of a metal-free domino synthesis of nicotinic acid derivatives from propargyl enol ethers and amines involving this spectacular cascade of chemical processes. Although these preliminary results constitute an excellent proof of concept, more experimental work needs to be developed to increase the efficiency of this pyridine synthesis. ${ }^{[16]}$

In summary, we have reported our preliminary results on the metal-free domino synthesis of substituted alkyl 1,2-dihydropyridine-3-carboxylates from propargyl enol ethers and primary amines via an unprecedented [3,3] propargyl-Claisen rearrangement - isomerization - amine condensation and $6 \pi$-aza-electrocyclization cascade reaction network. 1,2-Dihydropyridines $\mathbf{6}$ are obtained with remarkable high efficiency, good level of diversity (four possible diversity points) and bearing a convenient chemical handle for complexity-diversity generation (carboxylic ester at $\mathrm{C}_{3}$-position). This methodology has been extended to the synthesis of substituted nicotinic acid derivatives $\mathbf{1 0}$.

\section{Experimental Section}

Representative procedure for the microwave-assisted synthesis of 1,2-dihydropyridines 6. A solution of propargyl vinyl ether $1 \mathbf{a}(1.0 \mathrm{mmol})$ and $p$-anisidine $(\mathbf{4 a})(1.1 \mathrm{mmol})$ in toluene $(5 \mathrm{~mL})$ was placed in a microwave-special closed vial and the solution was irradiated for $30 \mathrm{~min}$ in a single-mode microwave oven $\left(150 \mathrm{Watt}, 120^{\circ} \mathrm{C}\right)$. The reaction mixture was dried over anhydrous sodium sulfate and filtrated using dichloromethane as solvent. After removing the solvent at reduced pressure the products were purified by flash column chromatography (silica gel, n-hexane/EtOAc 80/20) to yield 6aa $(100 \%) .{ }^{1} \mathrm{H}$ NMR $\left(400 \mathrm{MHz}, \mathrm{CDCl}_{3}, 25^{\circ} \mathrm{C}\right): \delta=3.73(\mathrm{~s}, 6 \mathrm{H}), 5.37\left(\mathrm{ddd},{ }^{3} J(\mathrm{H}, \mathrm{H})=9.8,5.3\right.$ and 0.8 $\mathrm{Hz}, 1 \mathrm{H}), 5.51\left(\mathrm{dpt},{ }^{3} J(\mathrm{H}, \mathrm{H})=5.3\right.$ and $\left.1.0 \mathrm{~Hz}, 1 \mathrm{H}\right), 6.49\left(\mathrm{dpt},{ }^{3} J(\mathrm{H}, \mathrm{H})=9.8\right.$ and $\left.1.0 \mathrm{~Hz}, 1 \mathrm{H}\right), 6.77(\mathrm{~d}$, $\left.{ }^{3} J(\mathrm{H}, \mathrm{H})=9.0 \mathrm{~Hz}, 2 \mathrm{H}\right), 6.98\left(\mathrm{~d},{ }^{3} J(\mathrm{H}, \mathrm{H})=9.0 \mathrm{~Hz}, 2 \mathrm{H}\right), 7.23-7.31(\mathrm{~m}, 5 \mathrm{H}), 7.79\left(\mathrm{dd},{ }^{3} J(\mathrm{H}, \mathrm{H})=1.0\right.$ and $0.8 \mathrm{~Hz}, 1 \mathrm{H}) ;{ }^{13} \mathrm{C} \mathrm{NMR}\left(100 \mathrm{MHz}, \mathrm{CDCl}_{3}, 25^{\circ} \mathrm{C}\right): \delta=\square 50.8,55.4,63.3,101.2,144.4,115.4,119.5$, 122.3, 125.5, 127.8, 128.9, 138.5, 142.2, 143.1, 157.1, 166.8; IR $\left(\mathrm{CHCl}_{3}\right) v$ bar= 3013.5, 1682.8, $1633.9,1567.7,1510.2,1440.5,1313.3,1269.1,1232.5,1108.0 \mathrm{~cm}^{-1}$; MS (70 eV): $\mathrm{m} / z(\%): 321(55)$ [ $\left.\mathrm{M}^{+}\right], 290$ (14), 262 (28), 245 (46), 244 (100), 201 (15), 115 (14), 92 (14), 77 (20); elemental analysis calcd (\%) for $\mathrm{C}_{20} \mathrm{H}_{19} \mathrm{NO}_{3}$ : C 74.75, $\mathrm{H}$ 5.96, N 4.36; found: C 74.76, H 5.85, N 4.55.

\section{Acknowledgements}

This research was supported by the Spanish Ministerio de Ciencia e Innovación, the European Regional Development Fund (CTQ2005-09074-C02-02 and CTQ2008-06806-C02-02) and the Spanish MSC ISCIII (RETICS RD06/0020/1046 and RD06/0020/0041), CSIC (Proyecto Intramural Especial 200719), FUNCIS (REDESFAC PI01/06 and 35/06) and the Fundación Instituto Canario de Investigación del Cancer (FICI-G.I.N808/2007). G.M.-A. thanks Spanish MEC for a FPU grant. 
[1]For recent reviews: a) J. P. A.; Harrity, O. Provoost, Org. Biomol. Chem. 2005, 3, 1349-1358; b) R. P. Hsung, A. V. Kurdyumov, N. Sydorenko, Eur. J. Org. Chem. 2005, 23-44.

[2]a) For recent progresses in this area, see: D. W. Hopper, K. M. K. Kutterer, J. J. Clemens in Progress in Heterocyclic Chemistry, Vol 20 (Eds:G. W. Gribble, J. A. Joule), Elsevier: New York, Chapter 6, Part 1, pp 294; b) G.-D. Zhu, W. H. Okamura, Chem. Rev. 1995, 95, 1877-1952; b) W. H. Okamura, A. R. de Lera in Comprehensive Organic Synthesis, Vol. 5 (Eds: B. M. Trost, I. Fleming), pergamon Press: London, 1991, Chapter 6.2, pp. 699-750.

[3]a) N. Sydorenko, R. P. Hsung, E. L. Vera, Org. Lett. 2006, 8, 2611-2614; b) Z. Vincze, Z. Mucsi, P. Scheiber, P. Nemes, Eur. J. Org. Chem. 2008, 1092-1100.

[4]For selected examples, see: a) T. Kobayashi, S. Hatano, H. Tsuchikawa, S. Katsumura, Tetrahedron Lett. 2008, 49, 4349-4351; b) B. M. Trost, A. C. Gutierrez, Org. Lett. 2007, 9, 1473-1476; c) K. Tanaka, H. Mori, M. Yamamoto, S. Katsumura, J. Org. Chem. 2001, 66, 3099-3110; d) D. F. Maynard, W. H. Okamura, J. Org. Chem. 1995, 60, 1763-1771;

[5]a) J. T. Binder, S. F. Kirsch, Org. Lett. 2006, 8, 2151-2153; b) H. Menz, S. F. Kirsch, Org. Lett. 2006, 8, 4795-4797; c) M. H. Suhre, M. Reif, S. F. Kirsch, Org. Lett. 2005, 7, 3925-3927; d) B. D. Sherry, L. Maus, B. N. Laforteza, F. D. Toste, J. Am. Chem. Soc. 2006, 128, 8132-8133.

[6]S. F. Kirsch, Synthesis 2008, 20, 3183-3204.

[7]For a precedent, see: W. Peng, S. Zhu, Tetrahedron 2003, 59, 4641-4649.

[8]L. F. Tietze, G. Brasche, K. Gericke in Domino Reactions in Organic Synthesis, WILEY-VCH, Weinheim 2006.

[9]a) D. Tejedor, A. Santos-Expósito, G. Méndez-Abt, C. Ruiz-Pérez, F. García-Tellado, Synlett 2009, 1223-1226; b) J. Inanaga, Y. Baba, T. Hanamoto, Chem. Lett. 1993, 241-244; c) for a seminal antecedent, see: E. Winterfield, Chem. Ber. 1964, 97, 1952-1958.

[10] a) Although conventional heating is sufficient, microwave irtradation proved to be more efficient; b) the metal-free [3,3] propargyl-Claisen rearrangement is a thermally-driven process and it is usually performed at high temperatures. A. Viola, J. J. Collins, N. Filipp, Tetrahedron 1981, 37, 3765-3811; c) for a recent example, V: Vaithiyanathan, K. Selvakumar, P. Shanmugam, Synlett 2009, 1591-1596;

[11]a) In the absence of this EWG, allenes 2 are stable enough to be isolated. For a seminal example, see: M. A. Henderson, C. H. Heathcock, J. Org. Chem. 1988, 53, 4736-4745; b) N. Krause, A. S. K. Hashmi in Modern Allene Chemistry, Wiley-VCH: Weinheim, 2004.

[12] A similar effect has been reported by Trost and col. in their ruthenium-catalyzed synthesis of pyridines (see reference $4 b$ ).

[13]For other examples of diastereoselective $6 \pi$-aza-electrocyclizations using chiral amines see: a) reference $4 \mathrm{a}$ and refereneces cited therein; b) K. Tanaka, T. Kobayashi, H. Mori, S. Katsumura, $J$. Org. Chem. 2004, 69, 5906-5925.

[14] Kirsch and col. have described that the one-pot multimetal-catalyzed reaction of primary amines and trisubstituted propargyl enol ethers $1\left(R^{1}=\mathrm{Ph} ; \mathrm{R}^{2}=\mathrm{Ph}, \mathrm{Et} ; \mathrm{R}^{3}=\mathrm{Me} ; \mathrm{Z}=\mathrm{CO}_{2} \mathrm{Et}\right)$ affords 1,2dihydropyridines in moderate yields (reference $5 \mathrm{a}$ ).

[15] Nicotinic acid is a relevant member of the vitamin B-complex family. For selected reviews, see; a) J. A. Farmer, Curr. Atherosclerosis Rep. 2009, 11, 87-92; b) J. B. Kirkland in Handbook of Vitamins (4th Edition) (Ed: J. Zempleni, R. B. Rucker, J. W. Suttie, D. B. McCormick), Taylor and Francis, Inc.: Boca Raton, 2007, pp. 191-232; c) C. Roderick, Appl. Catal., A 2005, 280, 75-82.

[16] Studies on the mechanism and synthetic improvement of these reactions are in progress in our group. 
Scheme 1. Proposed domino synthesis of 1,2-dihydropyridines from primary amines and propargyl vinyl ethers.

Figure 1. Modular and diversity-oriented synthesis of substituted 1,2-dihydropyridines 6 featuring four possible diversity points and one chemical handle (carboxylic ester at $\mathrm{C}_{3}$ ) for further complexity/diversity generation.

Scheme 2. Proof of concept: two-step versus domino reaction.

Scheme 3. Domino synthesis of substituted alkyl 3-pyridinecarboxylates (10) from propargyl enol ethers 1 and methoxyamine hydrochloride.

Table 1. Domino synthesis of 1,2-dihydropyridines $\mathbf{6}$ from propargyl enol ethers $\mathbf{1}$ and primary amines 4. ${ }^{[\mathrm{a}]}$

\begin{tabular}{ccccccccc}
\hline & $\mathbf{R}^{1}$ & $\mathbf{R}^{2}$ & $\mathbf{R}^{3}$ & $\mathbf{1}$ & $\mathbf{R}^{4}$ & $\mathbf{4}$ & $\mathbf{6}$ & Yield(\%) \\
\hline 1 & $\mathrm{H}$ & $\mathrm{Ph}$ & $\mathrm{H}$ & $\mathrm{a}$ & $\mathrm{pMeOC}_{6} \mathrm{H}$ & $\mathrm{a}$ & $\mathrm{a}$ & 100 \\
2 & $\mathrm{H}$ & $\mathrm{H}$ & $\mathrm{H}$ & $\mathrm{b}$ & “ & $\mathrm{a}$ & $\mathrm{b}$ & $51^{[\mathrm{b}]}$ \\
3 & “ & $\mathrm{Me}$ & $\mathrm{H}$ & $\mathrm{c}$ & “ & $\mathrm{a}$ & $\mathrm{c}$ & 87 \\
4 & “ & $n \mathrm{P}$ & $\mathrm{H}$ & $\mathrm{d}$ & “ & $\mathrm{a}$ & $\mathrm{d}$ & 71 \\
5 & $\mathrm{Ph}$ & $\mathrm{Ph}$ & $\mathrm{H}$ & $\mathrm{e}$ & “ & $\mathrm{a}$ & $\mathrm{e}$ & 95 \\
6 & $c \mathrm{H}$ & $\mathrm{Ph}$ & $\mathrm{H}$ & $\mathrm{f}$ & “ & $\mathrm{a}$ & $\mathrm{fa}$ & 55 \\
7 & $\mathrm{H}$ & $\mathrm{Ph}$ & $\mathrm{Me}$ & $\mathrm{g}$ & “ & $\mathrm{a}$ & $\mathrm{g}$ & $24^{[\mathrm{c}]}$ \\
8 & $\mathrm{H}$ & $\mathrm{Me}$ & $\mathrm{Me}$ & $\mathrm{h}$ & “ & $\mathrm{a}$ & $\mathrm{h}$ & $17^{[\mathrm{c}]}$ \\
9 & $\mathrm{H}$ & $\mathrm{Ph}$ & $\mathrm{H}$ & $\mathrm{i}$ & “ & $\mathrm{a}$ & $\mathrm{ia}$ & $80^{[\mathrm{d}]}$ \\
1 & $\mathrm{H}$ & $\mathrm{Ph}$ & $\mathrm{H}$ & $\mathrm{a}$ & $\mathrm{Bn}^{2}$ & $\mathrm{~b}$ & $\mathrm{a}$ & 83 \\
1 & “ & “ & “ & $\mathrm{a}$ & $\mathrm{Allyl}^{[\mathrm{e}}$ & $\mathrm{c}$ & $\mathrm{a}$ & 72 \\
1 & “ & “ & “ & $\mathrm{a}$ & $\mathrm{Ad}^{[\mathrm{e}]}$ & $\mathrm{d}$ & $\mathrm{a}$ & 87 \\
1 & “ & “ & “ & $\mathrm{a}$ & $\left(\mathrm{S}_{\mathrm{PhCH}}\right.$ & $\mathrm{e}$ & $\mathrm{a}$ & $83^{[\mathrm{f}]}$ \\
1 & “ & “ & “ & $\mathrm{a}$ & $\mathrm{PMB}^{[\mathrm{g}]}$ & $\mathrm{f}$ & $\mathrm{af}$ & 78 \\
1 & “ & “ & “ & $\mathrm{a}$ & $\mathrm{Ph}$ & $\mathrm{g}$ & $\mathrm{a}$ & 93 \\
1 & “ & “ & “ & $\mathrm{a}$ & $4-\mathrm{Cl}_{-} \mathrm{C}_{6} \mathrm{H}_{4}$ & $\mathrm{~h}$ & $\mathrm{a}$ & 88 \\
1 & “ & “ & “ & $\mathrm{a}$ & $\mathrm{pMeOC}_{6} \mathrm{H}$ & $\mathrm{a}$ & $\mathrm{a}$ & $100^{[\mathrm{h}]}$ \\
\hline
\end{tabular}

[a] Propargyl vinyl ether 1 ( 1 equiv), primary amine 4 (1.1 equiv) in toluene $(5 \mathrm{~mL}), 150$ watt, $120^{\circ} \mathrm{C}$, closed vessel, $30 \mathrm{~min} . \mathrm{Z}=\mathrm{CO}_{2} \mathrm{Me}$. Yield of isolated product. [b] 300 watt, $150{ }^{\circ} \mathrm{C}, 2 \mathrm{~h}$. [c] 300 watt, $150{ }^{\circ} \mathrm{C}, 3 \mathrm{~h}, \mathrm{Z}=\mathrm{CO}_{2}$ Et. [d] $\mathrm{Z}=\mathrm{SO}_{2}$ Tol. [e] Ad = Adamantyl. [f] $50 \%$ de. [g] PMB = pMethoxybenzyl. [h] Commercial (R)-1-phenylprop-2-yn-1-ol was used to prepare enantiopure (R)-1a. Product 6aa obtained as a racemic mixture. 


\section{Text for TOC:}

All at once: microwave irradiation of a metal-free mixture of propargyl enol ethers and primary amines generates substituted alkyl 1,2-dihydropyridine-3-carboxylates in excellent yields. The domino process involves an unprecedented [3,3] propargyl-Claisen rearrangement - isomerization - amine condensation and $6 \pi$-aza-electrocyclization cascade reaction network. The obtained 1,2-dihydropyridines feature four possible diversity points and a chemical handle for complexity-diversity generation (carboxylic ester at $\mathrm{C}_{3}$-position). This methodology has been extended to the synthesis of substituted nicotinic acid derivatives.

Keywords: Electrocyclic reaction • Claisen rearrangement • propargyl vinyl rearrangement • dihydropyridines $\bullet$ microwave 